\title{
The world I want - a world with less diabetes
}

\section{An open letter to Ban Ki-moon, Secretary General of the United Nations}

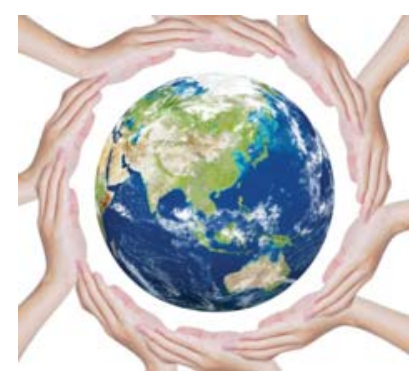

\section{Your Excellency,}

I am an Australian endocrinologist and academic with links to diabetes care in more than 45 countries. I am impressed by and congratulate all who contributed to the progress towards the Millennium Development Goals (MDGs). When committed people come together toward common goals, even ones as challenging as the eradication of poverty and illness on a global scale, much can be achieved.

\section{"Someone dies of diabetes every 6 seconds"}

In the post-2015 MDGs, I strongly recommend that global health, in particular diabetes, be given primacy, as "our health is our greatest wealth" and diabetes is already a global burden. The MDGs included a focus on communicable diseases, particularly HIV/AIDS, and substantial achievements resulted. Non-communicable diseases (NCDs), such as diabetes, already threaten human health and global development. NCDs account for almost two-thirds of deaths globally, with $80 \%$ of these deaths, often in young and middle-aged people, being in low- and middle-income countries. ${ }^{1}$

Someone dies of diabetes every 6 seconds. In 2013, there were 382 million people with diabetes globally, most in low- to middle-income countries, and this figure is predicted to rise to over 592 million within 25 years. $^{2}$ Most of this is preventable, but will require united global action. As you know, in 2006 the UN formally recognised the burden and importance of diabetes by the unanimous passing of Resolution $61 / 225$. $^{3}$ This resolution affirms diabetes as a major global health threat and encourages the development of sustainable national policies for diabetes prevention and care. Diabetes-related indicators are already being quantified, so we can monitor progress - an important factor in setting and reaching goals.

The personal and economic costs of diabetes are enormous. Diabetes is a chronic, usually incurable condition characterised by an absolute or relative lack of insulin, high blood glucose levels, abnormal blood lipid levels, and blood vessel damage that can affect every organ system. People of all ages, including babies in their mothers' wombs, may be affected by diabetes. People of all ethnicities, religions, occupations, geographies and socioeconomic groups can develop it. Diabetes is a common cause of vision

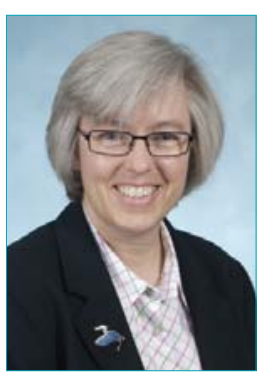

loss, kidney failure, heart disease, amputations, stroke, disability and premature death. As well as each person with diabetes, the disease affects their family, friends, colleagues and community, including the health care system, and the national and global economy.

On a daily basis, I see the negative impact that diabetes can have. I also know how much can be done to prevent it and to ease and save the lives of those with the condition. Sadly, I also know that resources are not equitably distributed. In 1939, as a child in a rural Australian community, my mother developed type 1 diabetes. With then recently available insulin injections and increasingly sophisticated medical care, she married, raised children, worked and volunteered, and lived until 91 years of age. In Australia, the European Union and the United States, I have worked with thousands of people with diabetes who live long and full lives.

Yet, from a global perspective, almost a century after Banting and Best's Nobel Prize-winning discovery of insulin, the commonest cause of death in a child with diabetes is lack of access to insulin. ${ }^{4}$ In low socioeconomic countries, I know of children who have died of diabetes within weeks of diagnosis because of lack of insulin, and of people who have developed blindness or kidney failure or required amputations due to lack of affordable drugs and health care. In disadvantaged regions, many people with diabetes are outcasts, deemed not marriageable, trainable or employable. Medical colleagues in disadvantaged countries tell me of people blinded by diabetes who have chosen to discontinue life-saving insulin so as to no longer burden their families. I have seen people hours from death from diabetes-related kidney failure, as no treatments were available in their country.

Through my work with two internationally active diabetes aid organisations, Insulin for Life (http:// www.insulinforlife.org) and the International Diabetes Federation's Life for a Child program (http://www. idf.org/lifeforachild), I have seen that many people working together have already substantially improved outcomes for people with diabetes in over 45 countries. We have found ways around many obstacles, including distance, language barriers, cultural challenges, need for health education, insufficient funding, lack of equipment and medication, and supply chain problems. Many important milestones have been met, but much remains to be done. As shown by our diabetes aid endeavours, and by the progress towards 
the MDGs, "the impossible can always be broken down into possibilities" (author unknown) and can be achieved.

Unfortunately, the global burden of diabetes is likely to increase unless we act now. With affluence, urbanisation and modernisation, sedentary lifestyles and obesity become more prevalent and, with these, diabetes incidence increases. Type 2 diabetes, traditionally regarded as a condition of middle-aged and older people, is now not uncommon in children, particularly in those from high-risk ethnic groups such as Indigenous Australians, Indians, Native Americans, Asians and people from the Middle East.

Prediabetes, a condition in which blood glucose levels are intermediate between normal and diabetes, is a major risk factor for type 2 diabetes, gestational diabetes and cardiovascular disease. It is also common and increasing. Medical research has shown that the risk of prediabetes and type 2 diabetes can be substantially reduced. Lifestyle choices related to a healthy diet, weight and physical activity are effective and low-cost. Such knowledge can be included in primary education and efforts to improve maternal health, as were the MDG

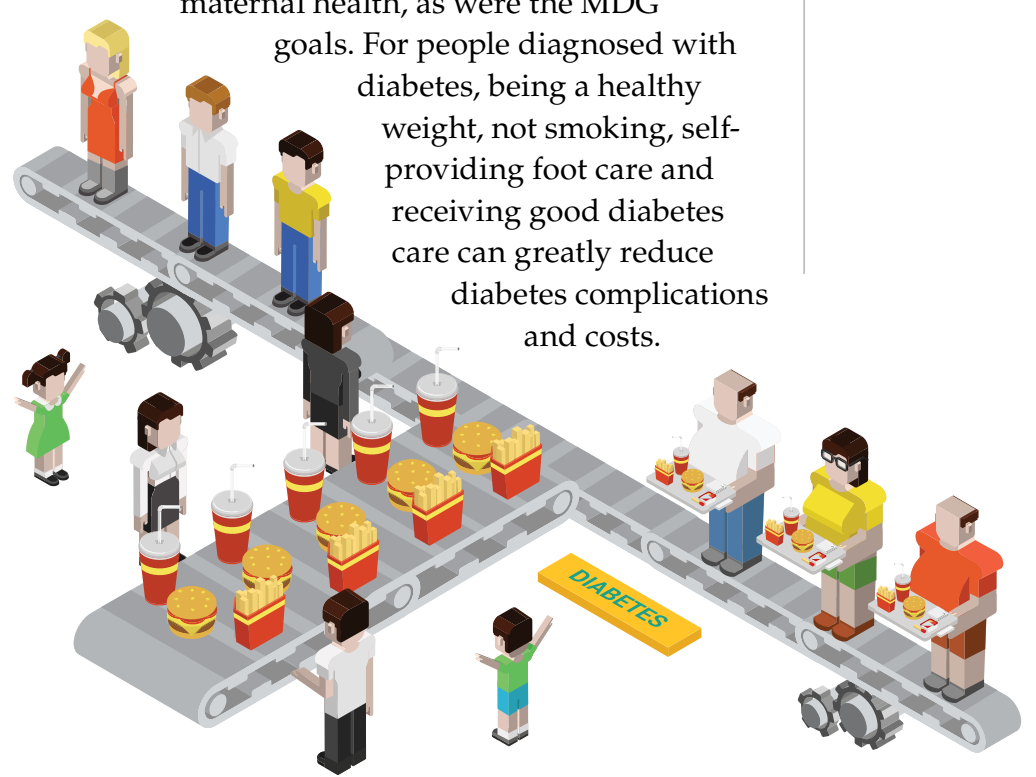

Malnourishment and gestational diabetes can adversely affect the health of the mother and of her offspring, even into adulthood, with increased risk of type 2 diabetes and cardiovascular disease. Diabetes, health, nutrition, agriculture, urban design, the environment, the economy and politics are all interconnected. Empowering women, better education, clean accessible water, food production and nutrition are well known to improve the health and economy of communities. Improving maternal health will reduce the risk of diabetes and cardiovascular disease in future generations. Improving diabetes care will reduce morbidity, health care costs and premature death. Lack of conflict, work opportunities, good urban design and stable governments with enlightened health policy will facilitate better health, including diabetes prevention and care. Diabetes may be regarded as a "canary in the coal mine", an indicator of many adverse global, local and individual factors, and can be used as a marker of the success of worthy endeavours that are likely to feature in the post-2015 MDGs.

A world with less diabetes and more equitable access to health care is a major part of "the world I want". There are many national and international organisations, including the International Diabetes Federation, Insulin for Life, national diabetes associations, and many community groups, health care professionals and individuals who are ready to help improve global health by reducing the burden of diabetes. Please do all you can to include health and diabetes as a post-2015 MDG. Much is at stake. Much needs to be done, yet there are many prepared to help.

Sincerely,

Alicia Jenkins

Competing interests: I am a board member of Insulin for Life (Australia and Global) and of Insulin for Life USA, and am an advisory panel member and collaborate with the International Diabetes Federation Life for a Child Program.

An extended interview with Professor Jenkins is available as a video at www. mja.com.au/multiimedia and as a podcast from iTunes and www.mja.com.au/ multimedia/podcastswww.mja.com.au/multimedia/podcasts 
1 Bloom DE, Cafiero ET, Jané-Llopis E, et al. The global economic burden of noncommunicable diseases. Geneva: World Economic Forum, 2011. http://www3.weforum.org/docs/ WEF_Harvard_HE_GlobalEconomicBurdenNonCommunicable Diseases_2011.pdf (accessed Jan 2015).

2 International Diabetes Federation. IDF diabetes atlas. 6th ed. Brussels: IDF, 2013. http://www.idf.org/sites/default/files/ EN_6E_Atlas_Full_0.pdf (accessed Jan 2015).

3 United Nations. Resolution adopted by the General Assembly: 61/225. World Diabetes Day. New York: UN, 2006. (A/ RES/61/225.) http://www.mopotsyo.org/WDD_Resolution. pdf (accessed Jan 2015).

4 Gale EAM. Dying of diabetes. Lancet 2006; 368: 1626-1628. . 